\title{
Design of Enterprise Information Systems: Roots, Nature and New Approaches
}

\author{
Jens Ove Riis \\ Center for Industrial Production, Aalborg University, Fibigerstraede 16, \\ DK-9220 Aalborg, Denmark
}

\begin{abstract}
As a scientific and professional discipline, the design of enterprise systems has undergone an impressive development. Today, it has achieved a well-established practice with clearly defined phases, tasks and methods. However, enterprises are challenged by increased complexity in their operations, externally imposed uncertainties and even unforeseeable events. Dynamic global operations call for speedy and effective responses to change. As a consequence, enterprises are challenged to adopt new approaches.

In view of this call for probing new roads, it seems useful to examine the roots of design in an effort to re-interpret many of the original ideas. In this paper, we shall briefly study significant contributions to decision-making, systems theory, project management, behavioral science and organization theory, as well as business aspects.

To further understand the nature of design, we shall discuss key features, such as purposeful intent based on a stakeholder approach, situational approach, integration of subsystems, perspectives and time horizons, the design process, and modeling.

Recent developments, e.g. in design science, design thinking, managing as designing, participatory design, and agile project management, have provided a number of new approaches that in many ways represent answers to the challenges of increased uncertainty and complexity. This has led to the development of seven propositions:
\end{abstract}

- $\quad$ Understanding mutual interplay of actors - unveiling self-sustaining informal learning processes

- Involving stakeholders - clarifying who wants to see the design succeed

- Accepting diversity - working with several perspectives in parallel

- $\quad$ Experimenting with new ideas - establishing a playful and creative mood among participants

- Enacting key features of new systems design - involving users in testing a series of prototypes

- Including the organizational context - orchestrating a design effort in view of simultaneous development initiatives and top management's shifting agenda 
- Acknowledging that the intentions of an enterprise information system are realized through people - An enterprise information system only sets the stage for organizational processes.

If adopted in an enterprise, management will be challenged to carry out design activities in a radically different way.

Keywords: Roots and nature of design, New approaches to design of enterprise information systems.

\section{Challenges to Design of Enterprise Information Systems}

As a scientific and professional discipline, design of enterprise information systems has undergone a remarkable development thanks to the impressive technological achievements and at the same time the acceptance by new users of new types of applications. Today, design of enterprise information systems is well established and widely recognized with a number of approaches and practices. It includes studies of management systems design as well as business processes.

However, significant changes are taking place in society and in companies resulting in new conditions for and requirements to designing new enterprise information systems. To mention some of them:

- Global markets and operations call for design and management of large networks of distribution and sourcing channels as well as of production plants. Companies are challenged to find a balance between branding global products and services and yet offering a local touch.

- Dynamic changes with many unforeseeable events stem from speedy technological development, the emergence of new markets, and political unrest in many parts of the world. This puts pressure on the stable parts of a company such as its organizational structure, management systems and competence profile. The time for reacting to change and for learning new skills has indeed become very short and calls for innovative responses.

- Complexity has increased, partly as a result of the above-mentioned trends. The technological development combined with competition has made it necessary to include knowledge into the design process at a high expertise level putting demands on organizing multi-disciplined teams. Furthermore, global product programs and management systems have become comprehensive with intricate interfaces. Many companies have experienced that it is not sufficient to focus on their own product program, and have engaged in developing complex business models that entail close cooperation with other companies in business networks.

These changes represent significant challenges and will call for radically new approaches to design of enterprise information systems. To be successfully implemented, they will also challenge management's attitude and managerial practice. 
Instead of just extending and adjusting current practice, we believe that it is useful to go back to the roots of design in an effort to re-interpret many of the original ideas. This will be the subject of the next section. Furthermore, we shall identify the nature of design in search of new developments and ideas. Before presenting new approaches, we shall discuss common behavioral responses to uncertainty and complexity.

We shall focus on design of enterprise information systems, but shall draw on approaches and practice in other application areas. The notion of design has always been, and still is, related to the solving of complex tasks requiring a consorted effort of several disciplines. The results are not only concepts or drawings, but realized, physical facilities, products or systems. Often design is defined as a transformation from a set of functional properties (requirements) to structural properties [1].

The notion of design has successfully been applied to a wide spectrum of different areas. Several disciplines have made design a central element, such as architecture, engineering, computer science, software engineering, media, art design and information systems. As a consequence, it has become difficult to define a specific set of methods and approaches to constitute design as a scientific discipline. Each application area calls for a specific approach, design process and methods, as reflected in a large number of recent comprehensive textbooks, e.g. [2], [3], [4], [5], and [6].

To illustrate such differences:

- In design of engineered facilities, usually a contract is the starting point for a design effort, and it also serves as a reference through the design process. On the other hand, design of information systems most often is characterized by a rather vague idea of the final result among both end-users and designers.

- Many engineering design efforts are carried out by a rather small group of individuals, whereas the anchoring of a new information system in the organization is a key issue, for which reason user involvement from the very start of the design effort represents an important challenge.

- Visualization of the expected results of a design process may often be rather easy, because the physical artifact lends itself to an intuitive explanation of its proper use. In contrast, design of business processes aims at developing a new way in which people interact in realization of a business model. A prototype or the final design of such business processes can only be visualized by enacting them.

\section{Roots of Design Theories}

Design may be considered as a scientific and professional discipline in its own right, e.g. supported by [7]. Over the years, several names have been associated with design activities, such as engineering design, design science and design thinking. In the German speaking countries, "Konstruktion" has been widely used for engineering design. The notion of design also includes the more artistic shaping of forms in architecture and industrial design. The various names represent different facets and approaches to design, and we shall try to include them in our discussion. However, for practical purposes, in this paper we shall use the term design as an all-embracing 
name, justified or not, and maintain a broad view of different application areas. Nevertheless we shall primarily focus on design of enterprise information systems.

It is necessary to view design as a scientific discipline in a different way than traditional disciplines, because of its unique nature of integration. As we shall discuss in the next section, design is essentially concerned with integrating a number of different disciplines and perspectives in such a way that it leads to a useful product or system.

Over the years, design has embedded thinking, approaches, principles, and methods from a number of disciplines. In the following, we shall discuss some of the most significant disciplines.

\section{Problem Solving and Decision-Making}

Operations Research and Management Science have made a significant contribution to normative theories of decision-making. Not only were mathematical methods developed and applied, e.g. linear programming and queuing theory, but scholars such as Ackoff [8] and Churchman [9] proposed ways of using scientific thinking to address and solve complex problems. Whereas many OR-researchers increasingly focused on developing techniques and methods for solving well-defined problems, especially Ackoff was concerned with adopting a broad systems approach to defining and scoping a problem. Looking back on his career, he asserts that "it is much better to do the right thing wrong than the wrong thing right, because when errors are corrected it makes doing the wrong thing wronger, but the right thing righter" [10].

Herbert A. Simon [11] and others studied how a rational problem solving process could be modeled. This served in many ways as a foundation for computer programs that would solve complex problems, e.g. playing chess, and thus for the growing field of artificial intelligent systems. But Simon was also very much concerned with adopting a broad multi-disciplinary approach to solving complex problems, which he called designing.

A behavioral approach to decision-making was adopted by Cyert \& March [12], and this led them to propose that individuals and groups in fact are satisficing rather than optimizing when they make decisions. A large number of studies of actual decision-making behavior has provided a useful supplement to the normative decision-making theories and methods, most prominently promoted by March, e.g. [13]. This approach also includes studies of decision-making in a political environment, e.g. [14].

\section{Systems Theory}

A system is commonly defined as "a collection of hardware, software, people, facilities, and procedures organized to accomplish some common objectives", cf. [3]. The idea of seeing a part of reality as a system with a clear distinction between what is included in the system and what is outside has had a remarkable influence on design, since it has allowed the breaking down of a complex system into a number of more manageable subsystems. It has also encouraged systems designers to look at the 
world outside the system, representing the environment in which the system eventually will operate. A key feature of systems theory is the working with two contrasting perspectives, respectively a holistic and an analytic approach [1]. A dialogue between these two perspectives is proposed by Riis [15].

In view of the very general nature of systems theory, the proposed typology of various systems by Bartalanffy [16] helped apply systems theory to a large number of different situations. The mutual interaction of parts of a system was studied by Forrester [17] and he developed a simulation program, Systems Dynamics, capable of identifying self-exciting processes and counter-intuitive behavior of systems when studied over time. Later on, this idea was used by Peter Senge to develop a significant contribution to organizational learning [18].

Cybernetics may be considered as a special part of systems theory concerned with steering (control) of systems [19]. With the technological development of computer capability, the underlying pursuit of automated decision-making has led to a renaissance of cybernetic thinking and the emergence of artificial intelligent systems and robots. However, attempts to also automate human thinking and behavior to its fullest extent have often neglected the fundamental difference between goal-seeking systems and purposeful systems (with human beings), as pointed out by Ackoff \& Emery [20].

A significant contribution has been made in the area of developing principles and methods for modeling systems, e.g. automation systems as well as planning and control systems, for example IDEF, GRAI, and Systems Modeling Language.

\section{Technical Disciplines}

Each design effort draws on contributions from a number of different disciplines, for example IT, electronics, mechanics, city planning, materials, and production. Each discipline has its own concepts, theories, methods, as well as standards for good professional practice. To a large extent this determines the phases of a design process.

Not neglecting this technical and professional foundation for design, it is however a challenge to find a way of integrating them into a combined process, which may be considered the core of a design effort, to be discussed in the next section.

\section{Project Management}

The field of project management has experienced a development parallel to design. Essentially, project management is concerned with the planning and organization of an effort to solve complex tasks. This also includes design activities.

In the 70s and 80s, project management focused on engineered facilities as well as product and systems design. Due to its success of introducing a new mode of organizing and managing teams cutting across departmental boundaries of the traditional hierarchical organizational structure, project management was also applied to other types of tasks; for example the introduction of new management methods, e.g. Total Quality Management, Total Productive Maintenance, Lean Thinking, many of which stem from Japan. 
In recent years, project management has been applied to organizational development in an effort to increase productivity, globalize its operation, and cooperate with other companies on new business models. This has drawn attention to the inclusion of behavioral elements, such as the creation of ownership, visualization of prototypes and dealing with stakeholders, cf. [21].

The parallel development of design and project management holds potential for a coordinated effort to exploit synergies.

\section{Behavioral Science and Organization Theory}

As mentioned above, decision-making has also been studied from a behavioral point of view leading to important insight into human behavior. This also includes studies of design processes, e.g. [22].

Scholars of design have also studied user involvement. For example, Binnekamp et al. [23] present a collaborative decision making process for architectural design, and Riis [15] elaborates on his experiences from a participatory approach to design of manufacturing visions.

Simon \& March [24] introduced an interesting way of viewing an organization, namely as a coalition of interests among actors. When joining an organization, an actor is committed to make a contribution and, in return, expects to receive a reward. An organization may be formed and survive if a coalition of individuals or groups finds that it is in their common interest to make a number of complementary contributions with the prospect of being awarded. If for some reason or other the balance between contribution and reward is no longer favorable compared to what the individual can obtain elsewhere, he or she may seriously consider leaving the organization.

This view of an organization may also apply to a design effort because of the existence of a large number of stakeholders with legitimate interests in a design, cf. [3], [23], and [15]. We shall discuss this approach in further detail in the next section.

A recent development, Managing as Designing, views management as a design discipline, [25]. Interestingly, their effort, in effect, also discusses the reverse sentence, that design is about organizing and managing [26].

However, most studies of design appear only to a minor extent to have made use of the potential of creating synergies between a predominantly normative planning approach and a behavioral approach. Two different worlds exist in parallel with their own journals, professional societies and departments at universities, making it daring and risky to survive in the academic world, if one attempts to cross over the ditch and introduce a multi-disciplinary approach. The research teams behind Design Thinking at Stanford and Potsdam address this issue with significant results [22], and in the foreword of [7] optimism is expressed with respect to linking design science and behavioral science stronger in the years ahead.

\section{Business Aspects}

When a contract forms the basis of a design effort, it is supposed to include relevant aspects of how the final design will create business value. However, in many design 
efforts uncertainties require that the business value be defined gradually during the design process. In this way, business aspects become an integral part of designing, and not something that is given at the outset.

The literature on business strategy represents an extensive set of principles, models and methods. An excellent overview of different schools of thought is offered by Mintzberg et al. [27].

In recent years, the notion of business models has emerged, cf. [28]. Although in its infancy, it signifies an acknowledgement that business value no longer may be created only by launching a new product. Rather, after-sales service, logistics, distribution channels (e.g. via internet) offer new ways of successfully doing business. Dell is a prominent example of being innovative in its sales channels. We have also seen that new businesses have been established resting on a close cooperation between companies with different specialties, in this way forming a business network, e.g. [29].

In conclusion, design appears as an amalgamation of a number of scientific contributions. Several thinkers of the root of design offer inspiration for modern systems design, for example to seek to the basics of a problem in order to formulate the "right" problem, to be aware of counter-intuitive effects of complex systems, to adopt a broad view of systems design, and to take note of organizational and managerial issues.

\section{The Nature of Design}

With the different ways of applying design with approaches and methods suited to the designers' specific situation, it is difficult to point to a generally accepted set of methods. However, it is useful, and necessary, if one wants to maintain design as a scientific and professional discipline, to seek a common understanding of the nature of design. The following is an attempt to do so, with the hope that it may be considered as a contribution to a constructive discussion that eventually my lead to a better understanding of the nature of design.

\subsection{Purposeful}

Although often tacitly assumed, a design effort signifies a concerted effort to improve current and future conditions. It is not sufficient to discuss issues, understand and explain phenomena, and to make decisions. The effort should lead to actions. This approach is supported by Ackoff \& Emery [20] who state that individuals perceive themselves as purposeful entities, acting in such a way that they intend to pursue a set of goals. This leads to a normative approach that is guided by an effort to develop a solution to a given task, it be a facility, a product or a system.

A normative approach does not preclude a descriptive approach. The former aims at assisting decision makers in formulating complex problems and in developing appropriate solutions, e.g. [8], [9]. The latter seeks to explain and understand interrelationships of a complex situation in an organization or in the interplay between several companies, e.g. [13] and [14]. As pointed out by Riis [1], Donaldson \& Preston [30] and Hevner et al. [31], the two approaches are mutually supportive 
because the normative approach provides directions for descriptive analyses, and the descriptive approach offers insight and understanding of how appropriate decisions may be reached.

Of the many obstacles to reach a jointly shared decision, the presence of different perceptions and opinions among a number of actors is perhaps the most significant difficulty. A stakeholder model may provide a framework for dealing with this situation.

\section{A Stakeholder Model}

As mentioned by Buede [3], stakeholders define the objectives of a systems design. However, they often have conflicting interests and expectations. A stakeholder model considers a good design as one that is approved by a powerful coalition of stakeholders, not necessarily by all stakeholders. The stakeholder approach seeks to go beyond the specified goals of a design effort by asking who are actually interested in seeing the project realized, and who would be against it, and furthermore, what results do they expect in order that they will call the final design a success. As a consequence, the notion of an optimal design, derived by an algorithm, thus makes little sense.

An implication of the stakeholder model is that a design is viewed as a means for a stakeholder to achieve his/her own goals. It is still important to define goals of a design, because they will indicate to stakeholders what the expected outcome of the design process will be, and thus serve as an important way of aligning stakeholders' expectations.

A stakeholder analysis may include identification of important stakeholders, assessment of their desired contribution and perceived reward, and an estimation of their reaction and behavior, cf. [32] and [21].

The stakeholder model addresses the question of where goals of a design come from, and how robust they are with respect to achieving the necessary support. Since expectations of stakeholders may point in different directions, it is important to develop a common platform, against which each stakeholder can mirror his/her own situation. Instead of focusing only on involvement of end-users, the stakeholder model thus suggests that a broader group of stakeholders somehow be involved.

\subsection{A Situational Approach - The Current Situation as Point of Departure}

A design effort aims to develop a unique solution to a specific design task. As an implication, much attention should be given to capture the nature of the design task, including an analysis of the current and future situation and environment in which the final design should function.

Based on many years of conversation with industrial managers, our impression is that it is far easier to present and discuss a specific solution than to describe a design task. For this reason there is a need to be able to capture the nature of the design task in a more operational way. 
Several methods are available for helping understand a design task. At the very general level, we have identified four different characteristics of a design task which identify the difficulty of dealing with a specific task [1]. They are

(i) uncertainty, e.g. to identify the nature of uncertainties in the face of commitments

(ii) complexity, e.g. to identify the origins of complexity (interaction of parts, complementary perspectives, or the need to combine different disciplines)

(iii) repetition and learning, e.g. to analyze if knowledge and experience exist from similar previous situations, and

(iv) conflicts of interest, e.g. to identify the nature of differences in perception, held belief and opinions among stakeholders.

The first two characteristics describe features of the task itself, while the third one captures characteristics of relationships between the design task and the individuals who are to be involved in the design effort, namely the extent to which they have prior knowledge and experience. The fourth characteristic describes interrelationships between individuals (actors).

Another way of capturing the design task is to identify the following three elements [33]:

- External conditions, originating from other parts of the enterprise and its environment,

- Internal constraints, such as current product portfolio, competences in the organization, and IT systems,

- $\quad$ Specified objectives, indicating management's decisions as to overall competitiveness.

Having been involved in developing production management systems in industrial companies for several decades, very often we have seen that there exists no deeper understanding of the overall interaction in an organization. Everybody is busy with his or her own task and takes little effort to discuss with colleagues how the overall processes are carried out. A rather simple method has been developed and widely used called a problem matrix, cf. [34] and [35]. At a workshop, each person or group of persons from the various sections and departments is asked to write down on yellow stickers the problems that he/she experiences. The stickers are placed on a wall under each section and grouped according to the type of problem. Usually, a distinction is made between problems imposed by other sections, internal problems, and problems sent on to other sections. By adding arrows connecting corresponding exported and imposed problems, it is possible to obtain a picture of the way in which sections are interacting. Tracing arrows may help identify and extract a handful of problem chains with self-exciting mechanisms. A common reaction from participants 
is a realization that, contrary to traditional theories of organization, no single person is to be blamed for the overall mal-functioning, but causes should be found in the interaction of persons.

Using Soft Systems Methodology to draw a Rich Picture is another approach to developing a mutual understanding of a complex situation with many actors [36].

There is much tacit knowledge underlying the complicated interaction of individuals, sections and departments when a business process is carried out, such as handling a customer order, developing a new product or system, or assuring quality and traceability of operations. To unveil this kind of knowledge, it is necessary to enact the pertinent business processes. Development of company-specific role-playing games represents a useful method for establishing a common understanding of the interplay around business processes, cf. [15].

Other methods exist for mapping business processes and value streams, cf. [37] and [38].

To conclude, more methods exist, but despite the ample assortment of methods for describing and analyzing the design tasks, there is a need to understand better why the development of a thorough understanding of current interplay in an organization attracts so little attention in theory and in practice.

\subsection{Integration of Subsystems, Perspectives and Time Horizons}

An engineered facility, product or system represents a whole that can function as a total of their interacting parts in accordance with desired performance. It is a challenging job to define a set of subsystems that will minimize their mutual interaction. This will also define where the most essential need for integrating subsystems is. A useful means of integration of subsystems is to develop and test prototypes even in the early phases of the design process, for example through simulation and enacting. This will enable the designers of each subsystem to study the interaction with other subsystems.

As already mentioned, many disciplines need to make a contribution and to be integrated in order to achieve a desired functionality. Furthermore, to understand the functioning of a design it should be studied from different perspectives.

Several authors have approached the issue of integrating disciplines and perspectives. Burbidge et al. [39] discuss integration inside a manufacturing function and across function boundaries. In particular, they note that consequences of decisions made in one function show up in other functions and thus call for an extra effort to integrate across functions.

Miles \& Snow [40] use an adaptive cycle to describe how an industrial enterprise develops its corporate strategy. They define three generic problems: (i) the Entrepreneurial Problem, (ii) the Engineering Problem, and (iii) the Administrative Problem. By addressing each problem in turn, eventually the adaptive process will lead to a well-balanced strategy. Riis et al. [41] have proposed a model for creating a dialogue between professionals and experts as part of developing a manufacturing vision. The key element is a series of Question-and-Answer sessions in which a facilitator or a participant asks a question pertaining to another domain. 
Although integration of subsystems, disciplines and perspectives has been acknowledged as an important issue, little attention has been given to the integration of time horizons. In general, with increased time horizon the degrees of freedom will become larger, primarily due to the fact that a design has to accept constraints imposed by existing systems, products and organization. A longer time horizon will allow for more options. It seems fair to claim that a given design is appropriate for a specific time horizon, and that a series of appropriate designs exists for a given set of time horizons.

On the one hand, a design should be able to solve short-term issues, and on the other hand it should not commit the users in such a way that the design will not be useful in the long run. Thus, a design should include future options and at the same time be useful in the shorter run. This represents a dilemma that may be called integration of time horizons.

The issue of integrating time horizons is related to the requirement of any organization to be able to handle both exploitation and exploration, cf. March [42]. As pointed out by Tushman \& Reilly [43], this requires an ambidextrous organization that is capable of hosting multiple and internally inconsistent architectures, competencies and cultures. Along the same lines, Boer [44] and Hyland \& Boer [45] have been concerned with combining incremental and radical innovation.

Especially because integration is a positive word with many good and beautiful connotations, it may be tempting to suggest that everything should be integrated. However, it is impossible to achieve this in practice. An important challenge, therefore, is to discuss where integration is needed, and where disintegration should be pursued. Lawrence \& Lorsch [46] address this discussion and illustrate that integration along one dimension may, as a natural consequence, leads to disintegration elsewhere, for example to choose between an organizational structure based on divisions according to a product/market segmentation or functions. Hence, it is important to discuss the need for integration and to be innovative with respect to identifying where and how integration should and can be realized.

\subsection{Design Process: Understand - Improve/Innovate - Apply}

It is understandable that there is a keen interest in finding out how the design process should proceed. There seems to be wide-spread agreement on three generic phases: (1) to understand the present situation and future challenges, (2) to develop a solution that may represent an improvement of an existing design or a new design, and (3) to implement the design in order to achieve the desired functionality and business value, e.g. [22].

In the traditional engineering design, the first effort includes an analysis of the current situation and the perceived need or opportunity for designing a new system or product, i.e. the design task is defined by specifying the desirable end result, cf. for example [47], [48], [49] and [50]. This forms the starting point for seeking one or more alternative design proposals to choose from. With complex design tasks usually the design phase is divided into a conceptual design and a detailed design phase. A proposed design is evaluated and eventually selected and implemented. 
At the more specific level, currently there seems to be a clash between a traditional model of design phases and new approaches, primarily stemming from a need to address uncertainties and unforeseeable events. In view of the uncertainty and complexity involved when a design effort is initiated, it is difficult at the outset to clearly define desired functional properties. On the other hand, analysis of a specific solution may serve as an inspiration for defining desired functional properties, i.e. using a circular design process as a sequential dialogue between exploring problem spaces (design task) and solution spaces (final design), cf. [1] and [51].

The traditional design process extends the three generic phases into five to eight phases, e.g. the seven stages in [2] and the Vee model described in [3]. The process is often seen as a one-way road where one phase is supposed to be completed before entering the next phase, indicated by the notion of "waterfall model". In a design environment where the design process is highly predictable, because of both a wellknown outcome and experienced design teams, this linear design process seems appropriate. One of its advantages is that all decisions pertaining to a phase are taken before entering the next phase.

However, the waterfall model is difficult to apply when many unforeseeable changes occur during the design process, and when it is difficult to specify the desired functionality of the design in the early phases. Several new models have appeared in an attempt to seek new approaches.

A cascade model was used in an industrial company introducing a new manufacturing vision entailing a new plant layout, management system, and a new organization. In the first place, top management agreed on the introduction of production groups and outlined a conceptual solution. Then production planners were asked to develop a new production planning and control system. Through participation in a workshop, the foremen were asked to design a new plant layout for their own production group, and finally, operators were asked to take part in a role-playing game as an introduction to discussing and planning their daily operations. In this way members of the organization were gradually involved in developing (designing) parts of the new production system. This process created a high degree of ownership.

A parallel design process has been proposed by several persons. Hein \& Andreasen [52] proposed a model called Integrated Product Development in which attention to sales/marketing, product design, and design of production system was carried out in parallel. The development of conceptual designs allowed for mutual adjustments and coordination between the three streams. Gudnason \& Riis [53] proposed a similar parallel stream process for the design of production systems.

In recent years, the notion of agility has been introduced as a response to a wish to maintain maneuverability in the light of an increasingly dynamic and unforeseeable environment. Disenchanted with the current mode of software development, assuming that customers and users know in advance what they want, a group of American software developers met to develop a manifesto on agile software development. In many ways, the manifesto signals a distinctly different approach to software development by preferring individuals and interactions to formal processes, working software is valued more than comprehensive documentation, customer collaboration is preferred to contract negotiation, and responding to change is valued higher than following plans. Some of the fathers of the manifesto have themselves written books 
on agile software development, e.g. Beck [54] and Highsmith [55]. Hirschfeld et al. [56] extend agile development processes with elements from the Design Thinking approach to make them even stronger and apply them to geographically dispersed software development teams.

\subsection{Modeling}

Models and modeling play an important role in design. As a simplified picture of the real world intended to capture certain features, a model is an expression of our knowledge within a certain area by way of the relationships between variables and parameters of the model.

In design, models are used to express our understanding of the current and expected future situation, e.g. a mapping of current business processes, the structure and functioning of a proposed design, either in a preliminary prototype version or as the final design, and a picture of the situation after the new designed system has been implemented.

A model will play different roles. For example, an IDEF model may serve as a blue print for software engineers to design an IT system, or a role-playing game may explain in action how a new management system will function and affect their future working life. We cannot expect that a single model may serve both purposes. To the contrary, we need a broad spectrum of models.

As a consequence, in the design of enterprise information systems many different models are used. IDEF models typically represent the backbone of software systems design, e.g. [3], whereas more soft models are used in discussions with stakeholders, including end-users. For example, Edelman et al. [57] and Luebbe et al. [58] report on the development of TBPM (Tangible Business Process Models) that includes the use of LEGO bricks, yellow stickers and role-playing activities in a series of iterations (prototypes).

Also at the conceptual level we have used models, called production management concepts and manufacturing visions, to express how in principle manufacturing may take place in the future [59]. As part of a participatory approach such models have primarily been used to provide a commonly shared picture of a future daily life, as a basis for discussion and redesign. Emphasis is on telling a story.

\section{Common Responses to Uncertainty and Complexity}

Over the years, we have observed how companies have responded to uncertainty, unforeseeable events and complexity. Although not based on a specific statistical survey, we shall claim that the following characteristics represent typical reactions that are also reflected in several studies of organizational behavior.

\section{Preoccupation with Daily Operations}

In recent decades, Danish companies have demonstrated significant improvements in their operations in terms of better quality, shorter and more precise delivery times, and increased productivity. However, competing companies have managed to do the same. 
On the other hand, very little focus has been placed on their capability to learn from daily operations, e.g. to extract patterns from the large amount of operational data that is available, and to systematize knowledge sharing. Furthermore, few companies are aware of increasing their capability of speedy and effective organizational changes. Most companies plunge into initiating major changes, as a response to external demand, without taking note of the organization's capability to change.

\section{Different Degrees of Uncertainty Are Dealt with by the Same Organizational Form}

In many of the planning situations involved in daily operations and in many design activities there is little room for including probability statements. Colleagues and external partners expect precise answers to delivery dates, to the manpower needed, to expected future sales of a new product, or to the scope of a new management system, etc. Even if the associated probability can be calculated or estimated, there are some fundamentally difficult issues related to making a decision under conditions of uncertainty. The organizational hierarchical structure, often with detailed performance indicators for each unit, does not encourage the inclusion of probability statements.

In addition, traditional organizational forms do not permit dealing with incidents that are not even perceived. Many organizational procedures and management systems are geared to provide only one response to coping with a broad spectrum of different situations.

\section{Complexity Syndrome}

We have often observed that managers and employees are not aware of the intricate interplay taking place in an organization whether it concerns daily operations or product development activities. Traditionally, a manager is supposed to display decisiveness and to be resolute. According to this role model of managers, action is preferred to contemplation. If lack of understanding of the complexity of a system is combined with the expected behavior of a manager, things may become critical. This combination may lead to what we call Complexity Syndrome, not understanding what is actually happening or the underlying behavioral mechanisms, and yet being obliged to make decisions pretending to have a comprehensive systems understanding. The results are a profusion of decisions demonstrating decisiveness, aimed at curing symptoms and not real causes.

\section{Self-excited Complexity}

Usually, complexity is considered a consequence of exogenously imposed factors, such as the call for a deeper knowledge of specialists, a multitude of markets with individual requests, and increased outsourcing of activities to international vendors. There are good reasons to take note of these factors. Sometimes, however, complexity is self-inflicted by the behavior of individuals, groups or the whole organization.

Consider a few examples:

- Engineers in new product development usually take professional pride in introducing the latest technology in their line of specialization. This often 
leads to advanced and complex solutions not necessarily in tune with the requirements of customers.

- Business processes are often adjusted to handle new situations, or improvements are implemented by adding new features. Over the years they may be dominated by a large number of exceptions and add-ons with few traces of the original business processes. Thus, the supporting systems and business processes themselves have become extra complex.

The examples show that complexity may increase inadvertently because of actions by individuals and groups.

\section{Self-sustaining Learning Processes}

An observation often made in a company is the existence of self-sustained learning processes that members of the organization are not aware of. One person responds to the activities of another person who in turn reacts to the first person's behavior. Due to informal and not intended feedback loops, such processes may, if not interrupted, lead to either a continuous deterioration or improvement of performance.

Consider two case examples:

- In an industrial company the production manager tried to cope with external changes by issuing many change orders, most often by shooting from the hip. It seemed that all externally imposed changes were sent directly on to production units without any filtering. The foremen were asked to make detailed planning in view of the workload and available capacity. In this way the production manager would be provided with valuable information about the actual and future work load and capacity which in turn would have made his own decisions more consistent. However, in the face of the many changes, the foremen eventually gave up trying to do thorough, detailed planning and resorted to ad-hoc planning decisions. Everybody was working hard and felt a constant pressure to deliver and to act. Sometimes a foreman would ask an operator to tear down the setting for one production order in the middle of its completion in order to do another production job. As a consequence, production performed poorly, and many frustrations indicated that the organization was working under great pressure.

- In an industrial company producing large equipment, the following result of mutual adjustments (organizational learning) could be observed. Sales often experienced that negotiations with customers would take longer time than first anticipated. Nevertheless, the delivery date for the equipment was kept. Engineering started their work when the contract was signed and wanted to do a good job. A master plan was prepared for the customer order, but this was not taken very seriously by engineering. Most often they delivered their detailed specifications late to purchasing and production. With the fixed delivery date, this led production to outsource part of the production processes and to move some of the assembly from being carried out in-house 
to on-site. As a result, extra costs were incurred, and both production and purchasing were working under great pressure. This was unfortunately not communicated to engineering. When asked about their opinion of the situation, they explained that their planning was guided by notice from production. "When they press us for the third time, we do our best to finish our job. And apparently they are very competent in production, because they always manage to deliver on time." So, engineering had learned that everything was working fine.

In some companies, such not intended inter-personal learning processes represent tacit knowledge and may constitute an essential part of the organization's core competence. On the other hand, they may also lead to overall poor performance and frustrations among organizational members, because they work hard but with unsatisfied results.

Similar learning processes have been presented sometimes under the label vicious and virtuous circles, e.g. [24], [1], [60], and [61].

\section{New Approaches and Methods - Seven Propositions}

Recent developments, e.g. in design science, design thinking, managing as designing, participatory design, and agile project management, have provided a number of new approaches that in many ways represent answers to the challenges of increased uncertainty and complexity, including the behavioral responses discussed in the previous section. This has given rise to developing seven propositions for systems design in such environments drawing on the recent developments, as well as the root and nature of design. For each proposition we shall give one or two illustrative case examples of how industrial enterprises have applied new approaches and methods.

\section{Understanding Mutual Interplay of Actors - Unveiling Self-sustaining Informal Learning Processes}

As discussed earlier, a key feature of design is the situational approach with emphasis on understanding the current situation. Several methods were mentioned, for example the problem matrix, soft systems methodology, and value stream mapping. Also prominent researchers representing the roots of design have pointed to the need to understand the often hidden dynamics of the present interplay in an enterprise, e.g. Forrester's disclosure of counter-intuitive effects of dynamic systems [17], and the need to ask unprejudiced questions in an effort to find the root of the problem, e.g. demonstrated by Ackoff [10].

- Case example: The manager of a small production firm once took time off from his busy daily schedule and filled-in elements of a problem matrix. This enabled him to identify a handful of problem chains with self-exciting elements. He could suddenly see that part of the complexity of managing the firm originated from his own reaction, and he was able to understand the behavior of his foremen. 
- Case example: Prior to be engaged in a major turn-around in a midsize enterprise, a seminar was held with managers and employees from all sections. They were asked individually and in groups to identify what caused the greatest problems in their daily working life.

Contrary to traditional organization theory according to which it is possible to find one individual who is responsible for a problem, the conclusion reached at the seminar was that the main cause of the problems was the mutual interplay between individuals and sections. It had created much complexity and prevented anybody to understand how the organization as a whole reacted, partly because of a number of self-sustaining vicious circles. This revelation created a strong support for and engagement in the subsequent organizational development initiative.

\section{Involving Stakeholders - Clarifying Who Wants to See the Design Succeed}

As mentioned earlier, stakeholders define the objectives of a systems design [3]. However, stakeholders often hold conflicting views and expectations. Therefore, the formulated objectives of a systems design may be viewed as an alignment of the wishes of a coalition of stakeholders. In view of the dynamics of systems design with internal and external changes, it is useful once in a while during the systems design project to ask who really wants to see the design project to be a success.

- Case example: In an enterprise information systems design project, the project manager spent much time in the beginning to involve stakeholders and to listen to their views and expectations. A set of objectives was formulated and gained general support. However when testing the conceptual design, the project manager realized that the formulated objectives could not be fully met. Through informal channels, stakeholders learned about the new situation and reacted negatively. The project manager felt very much alone with the project and decided to call stakeholders to a meeting to re-start the systems design project and ask them who actually wanted to stay on to see the project completed and under the new circumstances to discuss how this would be possible. In hindsight he would have wished that he had informed the stakeholders continuously to align their expectations to the real situation.

\section{Accepting Diversity - Working with Several Perspectives in Parallel}

Despite the fact that our environment increasingly becomes complex and difficult to comprehend, there is a tendency to ask for quick and simple answers. We are of the opinion that individuals and groups, in fact, are capable of dealing with complex and uncertain issues by drawing on their professional insight, intuition and common sense. But the organization in which they work rarely encourages this.

We shall propose a four-perspective model that encourages designers to adopt a multi-facetted view and thereby better be able to cope with complexity [62]. This is supported by Reimann \& Schilke [63] who state that "design thinking can be thought 
of as a methodology for innovation that systematically integrates human, business, and technical factors in problem-forming, problem-solving, and design."

Each perspective represents a specific angle or point of view and depicts essential features of an enterprise information system.

1. The entrepreneurial perspective. This perspective looks at the utility of the design, its benefits and costs. Attention is focused on clarifying and visualizing the benefit of the effort, and on justifying the cost incurred.

2. The technical perspective. This perspective is concerned with satisfying the technical constraints and requirements necessary for completion of the design effort and attainment of its objectives. Attention is focused on the technical specification, work breakdown structure of technical activities, and interfaces with surrounding systems and installations.

3. The organizational perspective. This perspective focuses on the formal and informal working modes employed, and on the development of motivation and knowhow among the persons to become involved in the planning and execution of the design effort.

4. The political perspective. This perspective looks at the stakeholders around the design effort and the potential and real conflicts of interests. Attention is focused on identifying relevant stakeholders and estimating their interests, their potential contribution to the project and their reward, as well as their attitudes, power and expected level of activities. The perspective is concerned with the question: Who wants to see the design completed and with which objectives?

Each perspective is based on a specific set of assumptions and focuses on a specific set of issues and phenomena. Theories and models explain interrelationships and indicate appropriate methods and procedures. Thus, each aspect enables us to draw a picture of the enterprise information system. In one sense it is limited by the angles used for viewing the initiative; in another sense the picture depicts the whole initiative. In the literature, a perspective often represents a certain school of thought; e.g. the entrepreneurial aspect reflects the business case and its strategic positioning and may draw on entrepreneurial strategic management schools providing methods for evaluating the market value of an initiative, cf. [27]. The organizational perspective offers conceptual ideas and theories for understanding the interaction between people involved in the initiative, and the political perspective provides a different kind of rationale based on power and influence.

The four perspectives will lead to four significantly different and complementary pictures. Instead of arguing which of the four perspectives gives the best and most correct picture of the enterprise information system and its situation, we shall maintain that we need all four perspectives to capture the essential features of a change task. However, their weight and importance may vary from one initiative to the other.

As pointed out by Lindberg et al. [51], design of IT systems tends to take place in an engineering expert world. The four-perspective model may be seen as an attempt to encourage the adoption of a broader view. In fact, the four-perspective model has been used in the initial stages of design processes to anticipate where most of the time and energy will be spent. To the surprise of many, the organizational and political 
perspective called for much attention. Also, in determining the rhythm of the design process, the four-perspective model has led to increased focus on creating ownership in the organization in which the new management system will be implemented, instead of letting technical issues be the primary determinant of the design process.

Dealing with one perspective may support the activities of another perspective. For example, a clear business case may encourage stakeholders to become more engaged and may set a scope and direction for technical issues. Also, involvement of members of the organization may stimulate development of innovative solutions.

- Case example: A group of specialists was engaged in developing a global logistic management and information system. They were very excited about their integrated model and were convinced that everybody would readily accept it. However, the group had not adopted an organizational perspective, because their model did not provide any answer to competences required and incentives. Nor did the group try to address issues like "what is in it for me?" Fortunately, the HR manager succeeded in changing the agenda to include the organizational perspective before the systems design was launched.

- Case example: An international company in the consumer goods industry once introduced the vision of "Direct Ordering" as a new way of fulfilling customers' orders. When a customer at a retailer shop had decided which product and which version to buy, the sales person would make an online request to the logistics department. A promised delivery date would be provided instantaneously, hopefully acceptable to the customer. A great effort in assembly and purchasing to reduce the through-put time had made it possible to guarantee a delivery time in Europe of less than five working days.

However, the Direct Ordering project dragged on and lasted for almost a year longer than first anticipated. When inquiring about the reason, in hindsight the logistics manager explained that the project had been assigned to the IT department, not realizing that the project would also touch on political and organizational issues. The project would short-cut the communication and have a heavy impact on the jobs of national dealers, district warehouses and the central warehouse. The logistics manager conceded that the project would have been handled differently had it not been perceived purely as an IT project.

\section{Experimenting with New Ideas - Establishing a Playful and Creative Mood among Participants}

Based on our experience with developing and running company-specific games and with creative workshops in which elements of a manufacturing vision have been developed, we have seen how organizational members (shop stewards, operators, middle managers, engineering staff, etc.), under proper guidance, are willing to engage in exploring and playing with new ideas. If many persons from the organization are involved, a common understanding is developed of possible directions for the company, including the need for new business processes. 
No commitments are necessarily made at this stage. However, if later on an opportunity occurs to move in a specific strategic direction, a broad awareness already exists of potentials and areas in need of attention.

We denote this playing with new ideas for probing into the future, adopted from Brown \& Eisenhardt [64]. They talk of exploring unknowable environment located on the edge of chaos at the same time as managing stable operations. To realize this, a spectrum of different working modes is necessary calling for different competencies and managerial mindset. However, practice shows that many companies are reluctant to allow for a more differentiated view of its business processes, guidelines and control mechanisms. Based on student projects, Skogstad \& Leifer [65] found that engineering designers gain important insight by experimentation, but managers and organizational procedures discourage them from a more playful exploration of innovative ideas.

We believe that a new managerial mindset and design practice is warranted to probe into the future by a participatory exploration of new business processes.

- Case example: During the process of developing a vision for a production unit that was responsible for making components important for the perception of uniqueness and quality of the products of an industrial enterprise, the relationship with suppliers was a key issue. Two different directions of a vision solution were defined

o The enterprise employees to be stationed at suppliers to ensure quality

- Suppliers' employees to be stationed with adequate machining tools at the enterprise to draw on their expertise.

Two groups explored how each of these ideas could be realized and were also asked to identify critical issues. Although the directions were different, it turned out that there were many overlaps in the solution elements and critical issues. This provided a sense of robustness and opened up for a more relaxed approach to the subsequent effort to define elements of the emerging manufacturing vision for the production unit. Thus, as the case example illustrates, it often spurs creativity to simultaneously explore two distinctly different directions.

\section{Enacting Key Features of New Systems Design - Involving Users in Testing a Series of Prototypes}

As already discussed, enterprise information systems support management and business processes that cut across organizational boundaries. Thereby it stimulates the mutual interplay between individuals, sections and departments. The planning process and information flow of the systems design may be tested by logical procedures and simulation, for example to study the robustness of a planning system. However, because the enterprise information system eventually will be used by individuals and groups through complex mutual interactions, a real test should involve an enactment 
of the proposed system among the future users. Following one of the principles of agile project management, a series of prototypes should be developed and tested by involving users.

- Case example: A young, small enterprise experienced a rather chaotic planning situation. An analysis showed that the production manager and planner themselves contributed to the stressful situation. A manufacturing vision was developed and visualized by making an analogy to the rules for traffic circles. In Denmark until the late 1980s traffic should give way to traffic coming from the right. As a result, with heavy traffic a circle would quickly be filled up. New rules for traffic circles were passed according to which the yielding rules were reversed giving way to traffic already in the circle. This meant that cars in traffic circle could easily drive through the traffic circle. Realizing that the company actually had followed the old traffic rules, the new manufacturing vision would follow the new rules cutting inprocess inventory and through-put times.

To test the proposed manufacturing vision, a simple company-specific game was developed with products and processes taken from the real company. It should last at most three hours, and all 45 employees should have an opportunity to play the game. One game run could accommodate 15 players. Methods for estimating the required capacity were introduced, and planning principles were tested. Not only did the participants engage themselves in trying out new ways of planning and executing production, but they were also taking active part in designing elements of the planning and information system.

\section{Including the Organizational Context - Orchestrating a Design Effort in View of Simultaneous Development Initiatives and Top Management's Shifting Agenda}

It may be tempting to focus on a single design effort, and much of the design literature does so. However, a survey of internal development initiatives suggested that organizational changes should also be looked at from a corporate point of view [66]. The study supported the observation that at any point in time a company has a wide spectrum of development initiatives in progress, including various design efforts, most of which are competing for the same resources and management attention. This suggests that a broader company-based view be adopted, and we have introduced the notion of orchestration. This indicates that management of internal development initiatives, similar to conducting an orchestra, is about harmonizing the activities of many interested parties into a concerted effort able to continuously shift the balance between actors and focal areas.

As an implication for design efforts, this suggests listening in on which development initiatives are in progress and considering if some of them may support the design effort and be joined into a coordinated development effort. Also, an opposite conclusion may have to be reached, that another initiative is in direct competition with the design project in question and ought to be discontinued. 
- Case example: A production manager wanted to initiate a drastic shift in the assembly of his company producing complicated equipment for the graphic industry offered in many variations. Instead of parallel assembly lines producing batches of given products, in the new assembly system the final assembly should be carried out by single operators working in parallel under the motto "One operator should produce one finished product per day". With new short-term inventory located next to the assembly cells, a drastic reduction of through-put time was estimated providing the flexibility that sales had wanted for years.

Well aware of the required change in mindset, the production manager decided to tie the introduction of the new assembly system to the introduction of a new, advanced product. Everybody knew that the new product was rather complicated and called for special attention. Therefore, it was easy to obtain support for the idea that the new product also deserved a new assembly system.

The project manager in charge of the new assembly system decided to build a prototype of a production cell next to the existing assembly lines. In this way, operators had an opportunity to ask about the new mode of assembly as the cell was built and tested. This also gave rise to many discussions and proposals.

\section{Acknowledging That the Intentions of an Enterprise Information System Are Realized through People - An Enterprise Information System Only Sets the Stage for Organizational Processes}

If a traditional, linear design process is followed, management, the design group, stakeholders and users are asked to make decisions on a weak knowledge basis. It is difficult early in the design process to imagine how the information system will function and affect each stakeholder.

So, even if a participatory approach is adopted with involvement of stakeholders and users, it is necessary to pay attention to visualizing the need to change, the basic idea of a new systems design, and the way in which the new system will function.

In addition, an organizational learning approach will often provide a better background for deciding the scope and objectives of a systems design as well as solution elements. It may be tempting when designing a new enterprise information system to focus attention primarily on the systemic aspects of business processes and to neglect how the people who eventually will use the system will react. This suggests that systems design be viewed as a learning process with several versions, instead of a once-for-all design based on limited knowledge.

- Case example: Supported by external consultants, the production manager of an industrial company wanted to change the plant from a traditional plant lay-out with sections for each type of production process to a manufacturing flow plant. During workshops it became clear that some of the foremen actually had proposed similar ideas years ago, but without gaining any 
interest from management at that time. Further analysis indicated that, in fact, it was possible to form two flow lines with existing machining tools. Many questions were asked indicating some uncertainty with respect to the effect on the daily working life of foremen and operators. Therefore, instead of asking production engineers to spend a couple of years designing "optimal" flow lines, it was proposed quickly to form one of the two lines of the existing machines and allow for an experimental period in which everybody would be involved in design of the actual processes, procedures and working modes.

- Case example: Two decades ago, management in a large industrial company had been convinced that time was ripe for introducing a new CAD system. Much effort was spent on studying the various commercial systems available on the market, including a comparison of their features. Finally, a system was selected and the implementation process started. After one year, the engineer in charge of this process was asked what he would have done differently if he was given the opportunity to make the decision again. His reply was that a more experimental approach would have been better, giving some groups of employees a 3-D system, another group a 21/2-D system, and a third group a 2-D system. This would have offered an opportunity for groups with different requirements to gain hands-on experience and an understanding of its potential, thus providing a broad and solid basis for planning the application of CAD in the near future. He admitted that very few in the organization at the time of the original decision had a good understanding of their needs and the capability of evaluating the various systems features.

The seven propositions do support one another and suggest a broader, multiperspective approach to design, an effort to understand the current interplay of individuals, sections and departments in business processes, a participatory approach based on stakeholder analysis and user involvement, and an experimental approach to play with new ideas and directions.

\section{Conclusion and Implications}

In this paper we have focused on how to design enterprise information systems under condition of uncertainty, dynamics and complexity. It was argued that new approaches and methods were necessary. Instead of just extending current practice, we went back to the roots of design to look for inspiration. This led to a review of major contributions to decision-making, systems theory, project management, behavioral science and organization theory, as well as business aspects. Several thinkers of the root of design offer inspiration for modern systems design, for example to seek to the basics of a problem in order to formulate the "right" problem, to be aware of counter-intuitive effects of complex systems, to adopt a broad view of systems design, and to take note of organizational and managerial issues. 
To further understand the nature of design, we discussed key features of design, such as purposeful intent based on a stakeholder approach, situational approach, integration of subsystems, perspectives and time horizons, the design process, and modeling.

Recent developments, e.g. in design science, design thinking, managing as designing, participatory design, and agile project management, have provided a number of new approaches that in many ways represent answers to the challenges of increased uncertainty and complexity. The paper concluded by presenting a number of propositions for systems design in such environments, drawing on recent developments, as well as the root and nature of design.

The propositions do support one another and suggest a broader, multi-perspective approach to design, an effort to understand the current interplay of individuals, sections and departments in business processes, a participatory approach based on stakeholder analysis and user involvement, and an experimental approach to play with new ideas and directions.

In its focus on challenges to cope with increased uncertainty and complexity, this paper has argued that new approaches and concepts need to be developed and adopted, in fact a re-conceptualization of enterprise information systems design. This has both theoretical and practical implications. The propositions point to new focal areas for research; for example increased research in the study of

- Integration of subsystems, perspectives and time horizons. As the technological development has led to an extensive specialization in all fields of society, a parallel development of means for integrating these areas of specialization has been widely neglected. This is, however, the essence of design, and research on integration needs to be strengthened, in tune with the origins of the design concept. As pointed out, research on integration should be seen as enacting an organizational process, including involvement of key stakeholders. This will require a new approach to design research. A better understanding and means of integration will have a significant impact on many areas of society far beyond design of enterprise information systems, due to the need for systemic and holistic thinking in view of the far-reaching specialization.

- Coping with uncertainty. We need more research on how to design enterprise information systems on the edge of chaos aimed at seeking a balance between exploiting existing means and approaches and exploring innovative solutions. This will require a multi-disciplinary effort to organize such a process at the same time as invariant patterns and elements are identified. It should also include the idea of postponing specific commitments to design solutions, yet securing a progressive design process.

Practical implications for design of enterprise information systems include increased focus on describing and understanding the corporate and organizational context in which the system will be developed and implemented, and on organizing the design process. It may be useful to join forces with the area of project management. 
Practical implications do not only pertain to designers but also to managers. The new approaches will challenge management to carry out design activities in a radically different way. For example, the design team should be given more leverage to experiment with new ideas, and organizational learning should be allowed to take place before committing decisions are made, for example by developing a systems vision that would allow postponement of key decisions until participants have obtained a clearer picture and understanding of the main idea of the new systems design. Managers would also need to develop organizational forms that can stimulate a systemic and holistic approach in view of traditional organizational forces to specialize in separate organizational units. The case examples have illustrated that it is, in fact, possible to work with new approaches and methods.

\section{References}

1. Riis, J.O.: Design of Management Systems - An analytical approach. Akademisk Forlag, Copenhagen (1978)

2. Ambrose, G., Harris, P.: Design Thinking. AVA Publishing, Lausanne (2010)

3. Buede, D.M.: The Engineering Design of Systems: Models and Methods, 2nd edn. Wiley \& Sons, New Jersey (2009)

4. Pahl, G., Beitz, W., Feldhusen, J., Grote, K.H.: Engineering Design - A Systematic Approach, 3rd edn. Springer, London (2007)

5. Keinonen, T., Takala, R.: Product Concept Design - A Review of the Conceptual Design of Products in Industry. Springer, Germany (2006)

6. Vaishnavi, V., Kuechler Jr., W.: Design Science Research Methods and Patterns Innovating Information and Communication Technology. Auerbach Publications, Taylor \& Francis Group (2008)

7. Hevner, A., Chatterjee, S.: Design Research in Information Systems - Theory and Practice. Springer, Heidelberg (2010)

8. Ackoff, R.A.: Scientific Method, optimizing applied research decisions. Wiley \& Sons (1962)

9. Churchman, C.W.: Prediction and optimal decision. Prentice-Hall (1961)

10. Ackoff, R.L.: On passing through 80. Systemic Practice and Action Research 12(4), 425-430 (1999)

11. Simon, H.A.: The Sciences of the Artificial, 3rd edn. The MIT Press, Cambridge (1996)

12. Cyert, R.M., March, J.G.: A Behavioral Theory of the Firm. Blackwell, Oxford (1964)

13. March, J.G.: A Primer on Decision Making, How Decisions Happen. The Free Press (1994)

14. Lindblom, C.E.: The science of 'muddling through'. Public Administrative Review, 79-88 (1959)

15. Riis, J.O.: Models for Company Development - A participatory approach taking manufacturing as point of departure. Center for Industrial Production, Aalborg University (2009)

16. von Bertalanffy: General Systems Theory: Foundations, development, applications. Penguin, London (1973) (original American publication 1968)

17. Forrester, J.: Industrial dynamics. MIT Press, Cambridge (1961)

18. Senge, P.: The Fifth Discipline. Century Business (1993) 
19. Wiener, N.: The Human use of Human Beings: Cybernetics and Society, revised edition. Houghton Mifflin, Boston (1954)

20. Ackoff, R.L., Emery, F.E.: On Purposeful Systems. Aldine-Atherton, Inc., Chicago (1972)

21. Mikkelsen, H., Riis, J.O.: Fundamentals of Project Management (in Danish: Grundbog i Projektledelse). Prodevo, 10th edn. An English summary (2010),

http: / /www. prodevo.dk

22. Plattner, H., Meinel, C., Leifer, L. (eds.): Design Thinking: Understand - Improve Apply. Springer, Heidelberg (2011)

23. Binnekamp, R., van Gunsteren, L.A., van Loon, P.-P.: Open Design, a Stakeholderoriented Approach in Architecture, Urban Planning, and Project Management. IOS Press, Amsterdam (2006)

24. Simon, H.A., March, J.G.: Organizations. Wiley \& Sons, New York (1958)

25. Richard Jr., J.B., Collopy, F. (eds.): Managing as Designing. Stanford University Press, Ca (2004)

26. Weick, K.: Rethinking Organizational Design. In: Richard Jr., J.B., Collopy, F. (eds.) Managing as Designing, pp. 36-53. Stanford University Press, Ca (2004)

27. Mintzberg, H., Ahlstrand, B., Lampel, J.: Strategy Safari, A Guided Tour Through the Wilds of Strategic Management. Prentice Hall Europe (1998)

28. Osterwalder, A., Pigneur, Y., Tucci, L.C.: Clarifyng business models: Origins, present, and future of the concept. Communications of AIS (16), 1-25 (2004)

29. Lindgren, P., Taran, Y., Boer, H.: From single firm to network based business model innovation. International Journal of Entrepreneurship and Innovation Management 12(2), 122-137 (2010)

30. Donaldson, T., Preston, L.E.: The stakeholder theory of the corporation: Concepts, evidence, and implications. Academy of Management Review 20(1), 65-91 (1995)

31. Hevner, A., March, S., Park, J., Ram, S.: Design science in information systems research. MIS Quarterly 28(1), 75-105 (2004)

32. D’Herbemont, O., César, B.: Managing Sensitive Project. MacMillan Press (1998)

33. Riis, J.O.: The use of production management concepts in the design of production management systems. International Journal of Production Planning \& Control 1(1), 45-52 (1990)

34. Johansen, J., Mitens, L.: Methods for Analysis and Diagnosis of Production Management (in Danish). Aalborg University \& Technical University of Denmark (1986)

35. Riis, J.O.: Situational production management: a practical theory for the development and application of production management. International Journal of Production Planning \& Control 5(3), 240-252 (1994)

36. Checkland, P., Scholes, J.: Soft Systems Methodology in Action. John Wiley \& Sons (1999)

37. Rentzhog, O.: Process orientation - A foundation for modern management (in Danish) Studentlitteratur (2000)

38. Bicheno, J.: The Lean Toolbox. Piscie Books, Buckingham (2000)

39. Burbidge, J.L., Falster, P., Riis, J.O., Svendsen, O.: Integration in Manufacturing. Computers in Industry 9, 297-305 (1987)

40. Miles, R.E., Snow, C.C.: Organizational Strategy, Structure and Process. McGraw-Hill, New York (1978)

41. Riis, J.O., Dukovska-Popovska, I., Johansen, J.: Participation and dialogue in strategic manufacturing development. Production Planning and Control 17(2), 176-188 (2006)

42. March, J.G.: Exploration and Exploitation in Organizational Learning. Organization Science 2, 71-87 (1991) 
43. Tushman, M.L., O’Reilly III, C.A.: Ambidextrous organizations: managing evolutionary and revolutionary change. California Management Review 38(4) (1996)

44. Boer, H.: And [Jethro] said.. Learning: the link between strategy, innovation and production, Inaugural lecture. Center for Industrial Production, Aalborg University (2001)

45. Hyland, P., Boer, H.: A continuous innovation framework: Some thoughts for consideration. In: Proceedings of the 7th International CINet Conference 2006: CI and Sustainability - Designing the Road Ahead, pp. 389-400. University of Brighton, CENTRIM (2006)

46. Lawrence, P., Lorch, J.: Organization and Environment. Division of Research, Graduate School of Business Administration. Harvard University (1967)

47. Asimow, M.: Introduction to Design. Prentice Hall (1962)

48. Krick, E.: An Introduction to Engineering and Engineering Design, 2nd edn. J. Wiley (1969)

49. Pressman, R.S.: Software Engineering - A Practitioner's Approach, 5th edn. McGraw-Hill, London (2000)

50. Sydenham, P.: Systems Approach to Engineering Design. Artech House, Inc., Norwood (2003)

51. Lindberg, T., Meinel, C., Wagner, R.: Design Thinking: A Fruitful Concept for IT Development? In: Plattner, H., Meinel, C., Leifer, L. (eds.) Design Thinking: Understand Improve - Apply, pp. 3-20. Springer, Heidelberg (2011)

52. Hein, L., Andreasen, M.M.: Integrated Product Development (in Danish). The Confederation of Danish Industries (1985)

53. Gudnason, C.H., Riis, J.O.: Manufacturing Strategy. OMEGA 12(6), 547-555 (1984)

54. Beck, K.: Extreme Programming Explained. Addison-Wesley (2000)

55. Highsmith, J.: Agile Project Management - Creating Innovative Products. Pearson Education (2004)

56. Hirschfeld, R., Steinert, B., Lincke, J.: Agile Software Development in Virtual Collaboration Environments. In: Plattner, H., Meinel, C., Leifer, L. (eds.) Design Thinking: Understand - Improve - Apply, pp. 197-218. Springer, Heidelberg (2011)

57. Edelmann, J., Currano, R.: Re-representation: Affordances of Shared Models in TeamBased Design. In: Plattner, H., Meinel, C., Leifer, L. (eds.) Design Thinking: Understand Improve - Apply, pp. 61-79. Springer, Heidelberg (2011)

58. Luebbe, A., Weske, M.: Bringing Design Thinking to Business Process Modeling. In: Plattner, H., Meinel, C., Leifer, L. (eds.) Design Thinking: Understand - Improve - Apply, pp. 181-195. Springer, Heidelberg (2011)

59. Riis, J.O., Johansen, J.: Developing a manufacturing vision. Production Planning and Control 14(4), 327-337 (2003)

60. Argyris, C.: On Organizational Learning. Blackwell, Oxford (1992)

61. March, J.G., Levitt, B.: Organizational Learning. Annual Review of Sociology 14, 319-340 (1988)

62. Riis, J.O., Mikkelsen, H.: Capturing the nature of a project in the initial phase - Early identification of focal areas. International Journal of Project Management 3(1), 18-22 (1997)

63. Reimann, M., Schilke, O.: Product Differentiation by Aesthetic and Creative Design: A Psychological and Neural Framework of Design Thinking. In: Plattner, H., Meinel, C., Leifer, L. (eds.) Design Thinking: Understand - Improve - Apply, pp. 45-60. Springer, Heidelberg (2011) 
64. Brown, S.L., Eisenhardt, K.M.: The Art of Continuous Change: Linking Complexity Theory and Time-paced Evolution in Relentlessly Shifting Organizations. Administrative Science Quarterly 42, 1-34 (1997)

65. Skogstad, P., Leifer, L.: A Unified Innovation Process Model for Engineering Designers and Managers. In: Plattner, H., Meinel, C., Leifer, L. (eds.) Design Thinking: Understand Improve - Apply, pp. 19-44. Springer, Heidelberg (2011)

66. Mikkelsen, H.: Managing the Myriad of Projects (in Danish: Ledelse af Projektmylderet). Børsens Forlag, Copenhagen (2005) 